\title{
La protección del patrimonio arqueológico subacuático, competencias sancionadoras de la Comunidad Autónoma de Andalucía: Caso Odyssey.
}

\author{
Mónica Ortiz Sánchez \\ Letrada de la Junta de Andalucía \\ María del Amor Albert Muñoz \\ Letrada de la Junta de Andalucía
}

\begin{abstract}
SUMARIO: I. INTRODUCGIÓN. II. ANTECEDENTES Y RESUMEN DE LA SENTENCIA. III. ANÁLISIS DE LOS RAZONAMIENTOS Y DOCTRINA QUE CONTIENE LA SENTENCIA: 1. Caducidad, 2. Non bis in ídem, 3. Incompetencia por ser el pecio propiedad del Reino Unido, 4. Incompetencia de la Junta de Andalucía para sancionar en el mar territorial, 5. Incompetencia de la Junta de Andalucía y competencia del Estado en virtud del real decreto 799/81, 6. Hechos ocurridos en aguas españolas. IV. COMENTARIO.
\end{abstract}

\section{INTRODUCGIÓN}

La Sala de lo Contencioso Administrativo del Tribunal Superior de Justicia de Andalucía, con sede en Sevilla, ha resuelto en la Sentencia de 26 de mayo de 2010 el Recurso 396/2007 presentado por Odyssey Marine Exploration Inc. contra la Orden de la Consejería de Cultura de 10 de abril de 2007, por la que se estima parcialmente el recurso de alzada interpuesto contra la resolución del Director General de Bienes Culturales, por la que se impone a la actora una sanción por infracción de la Ley 1/91 de Patrimonio Histórico de Andalucía por realización de actuaciones arqueológicas sin autorización, fijando la cuantía de la multa en 60.101,21 euros. 


\section{El Ponente ha sido el Ilmo. Sr. D. Eugenio Frías Martínez.}

Esta sentencia es digna de un comentario por diversas razones: por la repercusión internacional de los hechos que dieron lugar, entre otros procesos, al procedimiento sancionador que ahora se analiza, y que curiosamente ha sido el menos conocido, y por la doctrina que fija en relación a las competencias de las Comunidades Autónomas en la protección del patrimonio arqueológico subacuático. $^{1}$

Esta Sentencia, junto con la del Tribunal Federal de EE.UU., confirma la imposibilidad de los cazatesoros de actuar en cualquier parte del mundo de forma impune, expoliando el patrimonio arqueológico subacuático y confirma la necesidad de sujetar este tipo de actividades a una serie de controles administrativos. A saber, que el mundo de los piratas hace tiempo que quedó atrás.

\section{ANTECEDENTES Y RESUMEN DE LA SENTENCIA}

Los hechos que acontecieron desde el año 2001 hasta la actualidad, con la reciente sentencia que aquí se comenta (2010) y con la del Tribunal Federal de EE.UU. (2009), han sido objeto de análisis en numerosos artículos publicados en revistas especializadas ${ }^{2}$ y por ello no vamos a profundizar en ellos en esta

\footnotetext{
${ }^{1} \mathrm{Ha}$ de recordarse que hasta la fecha la única definición del patrimonio cultural subacuático es la prevista en la Convención sobre la protección del Patrimonio Cultural Subacuático, hechaen París el 2 de noviembre de 2001, y ratificada por España mediante Instrumento de ratificación de 25 de mayo de 2005 (BOE 5 de marzo de 2009). Artículo 1.Definiciones. A los efectos de la presente Convención: 1. (a) Por "patrimonio cultural subacuático" se entiende todos los rastros de existencia humana que tengan un carácter cultural, histórico o arqueológico, que hayan estado bajo el agua, parcial o totalmente, de forma periódica o continua, por lo menos durante 100 años, tales como: (i) los sitios, estructuras, edificios, objetos y restos humanos, junto con su contexto arqueológico y natural; (ii) los buques, aeronaves, otros medios de transporte o cualquier parte de ellos, su cargamento u otro contenido, junto con su contexto arqueológico y natural; y (iii) los objetos de carácter prehistórico.

${ }^{2}$ Se citan a continuación las principales publicaciones que se han realizado sobre este asunto hasta la fecha: Elisa Marina Álvarez González, Disfuncionalidades de la protección jurídica del patrimonio cultural subacuático en España. Especial referencia al caso Odyssey. Revista de Administración Pública núm. 175, enero-abril (2008), páginas 323-273, Madrid; Elsa Marina Álvarez González (dir.), Patrimonio arqueológico sumergido: una realidad desconocida, Universidad de Málaga, Servicio de Publicaciones, 2009; José Juste Ruiz, Buques de estado hundidos y protección del patrimonio cultural subacuático: el llamado caso Odyssey, en Derecho internacional y comunitario ante los retos de nuestro tiempo: homenaje a la profesora Victoria Abellán Honrubia, Marcial Pons, 2009; María Ampa-
} 
reseña de jurisprudencia más allá de lo estrictamente necesario al objeto del comentario que se va a realizar del pronunciamiento del Tribunal Superior de Justicia en relación al procedimiento sancionador tramitado por la Consejería de Cultura de la Junta de Andalucía.

Así pues los hechos, resumidos de forma muy concreta, consisten en la realización por parte de la empresa Odyssey Marine Exploration Inc. de actuaciones de investigación y prospección arqueológica, unidas a otras de extracción de piezas arqueológicas (especialmente una considerable suma de monedas de oro y plata) de un barco español, Nuestra Señora de las Mercedes, en aguas territoriales españolas, sin contar con las autorizaciones necesarias.

La actuación de Odyssey Marine Exploration Inc. en aguas españolas realizando actividades de prospección arqueológica y de extracción de monedas de oro de un buque español ha recibido una cobertura mediática a nivel nacional e internacional extraordinaria no sólo por lo exótico del tema (buques de guerra, tesoros hundidos, problemas internacionales) sino también por los diversos actores que han participado en los hechos (la propia empresa, el Reino Unido, EE.UU., la Administración del Estado en España y de la Junta de Andalucía). Afortunadamente la historia ha tenido un final feliz al confirmar el Tribunal Federal de EE.UU. la sentencia del Juez de instancia, Mark Pizzo, en la que ordenaba a la empresa la devolución de las monedas al Estado Español. Este litigio transnacional entre el Estado Español y la empresa que se ha desarrollado en tribunales estadounidenses no es sin embargo el único litigio al que dieron lugar los hechos ya por todos conocidos.

La Junta de Andalucía incoó un procedimiento sancionador a la empresa que ha terminado con una resolución sancionadora confirmada por los tribunales y ya firme en la que se ratifica la competencia de la Junta de Andalucía para sancionar a aquellas empresas o personas que realizan actividades arqueológicas en el mar territorial español sin la debida autorización.

ro Alcoceba Gallego, Algunas consideraciones sobre los aspectos competenciales del caso Odyssey y el régimen de protección del Patrimonio Subacuático español, en La protección jurídico internacional del patrimonio histórico: especial referencia a España, Colex, 2009; Sarah Dromgoole, Murky waters for government policy: the case of a 17th century British warship and 10 tonnes of gold coins, Marine Policy 28 (2004), págs. 189 a 198; Mariano J. Aznar Gómez, España y el patrimonio cultural subacuático: algunos problemas jurídicos, Revista de la Facultad de Derecho de la Universidad de Granada, $\mathrm{N}^{\circ} 10$, 2007 (Ejemplar dedicado a: Arte, Cultura y Derecho) págs. 203-238. 
Esta sentencia aborda varias cuestiones de gran calado y servirá seguramente de precedente para futuros casos que puedan surgir dada la riqueza de las aguas españolas en materia de buques hundidos debido a su propia historia y situación geográfica privilegiada. Entre las cuestiones que se abordan son especialmente interesantes las relativas a la competencia de la Comunidad Autónoma para sancionar en relación al patrimonio arqueológico subacuático, permanentemente cuestionada por la recurrente, y que finalmente es reconocida por la Sala en varios fundamentos ampliamente motivados. No sólo se basa la Sala en el reconocimiento estatutario de las competencias sobre patrimonio histórico que se extienden al mar territorial sino que vuelve a recordar la doctrina de los tribunales sobre la diferencia entre la titularidad de los bienes (demanio público) y la posibilidad de que concurran distintas administraciones sobre unos mismos bienes ejerciendo distintas competencias.

También tiene especial relevancia el tratamiento del principio non bis in ídem y la relación entre el procedimiento administrativo y el penal. Y ello porque se incoaron Diligencias Previas en los Juzgados de la Línea de la Concepción por un delito de desobediencia a la autoridad al negarse el capitán del buque Seahawk (el barco empleado por Odyssey Marine Exploration Inc. para realizar las actividades sancionadas) a atender los requerimientos de la Guardia Civil Española.

Precisamente, como se ha indicado anteriormente, una de las cuestiones abordadas en la sentencia es la alegación de la recurrente de que se estaría vulnerando el principio non bis in ídem sobre la pretendida base de la existencia, junto al procedimiento sancionador seguido por la Administración de la Junta de Andalucía, de dos Diligencias Penales abiertas por los Juzgados de Instrucción de la Línea de la Concepción, Cádiz, referidas supuestamente a los mismos hechos, de las cuales la actora interesó la practica de prueba al objeto de acreditar la supuesta identidad.

Sin embargo, como razona la sentencia, no existía la pretendida identidad de sujetos, objeto y bien jurídico protegido, precisa para que se produzca el efecto del principio non bis in ídem.

De hecho, de la actuación de la actora realizando actividades arqueológicas subacuáticas sin la oportuna autorización, no sólo se derivó la incoación del sancionador administrativo que nos ocupa y la apertura de Diligencias Penales, sino que, también dio lugar a un procedimiento de reivindicación del tesoro hallado, seguido ante los Tribunales de Tampa, Florida, procedimiento para determinar la titularidad del hallazgo. 


\section{ANÁLISIS DE LOS RAZONAMIENTOS Y DOCTRINA QUE CON- TIENE LA SENTENCIA}

Se van a analizar a continuación los pronunciamientos de la sentencia más relevantes indicándose de forma sucinta en el título de cada apartado su contenido, reproduciendo a continuación en cursiva el texto de cada fundamento y analizándolo seguidamente.

\section{Gaducidad}

SEGUNDO.- Se alega la caducidad del expediente sancionador, por haberse superado el plazo de seis meses, desde la incoación hasta la notificación de la resolución del recurso de alzada.

El plazo de duración del procedimiento se inicia con la incoación y finaliza con la notificación de la resolución sancionadora, sin que se compute en el mismo los plazos de interposición y resolución de los posibles recursos que se interpongan en vía administrativa.

La incoación se efectuó el 16 de marzo de 2006, habiéndose dictado resolución sancionadora el 31 de julio de 2006, notificada el día 28 de agosto siguiente, no habiéndose superado el plazo de seis meses, no es posible estimar la caducidad alegada.

Aborda en primer término la sentencia, la cuestión de la caducidad del procedimiento ya que, efectivamente, de existir ésta, procedería declarar la nulidad del procedimiento sin más trámite.

Sin embargo, tal alegación que la recurrente pretendía fundamentar incluyendo en el cómputo del plazo del procedimiento sancionador, el plazo para resolver el recurso de alzada, es desestimada por la sentencia, ya que dicho plazo, de seis meses, ha de computarse desde la incoación hasta la notificación de la resolución, sin perjuicio, claro está, del eventual recurso de alzada, cuyo cómputo, no se incluye dentro de este plazo establecido para el procedimiento.

\section{Non bis in idem}

TERCERO.-Aun cuando no se recoge de forma expresa en la demanda, en el escrito de conclusiones se mantiene la vulneración del principio de "non bis in idem" al seguirse por los mismos hechos Diligencias Previas $13 / 06$ del Juzgado de Primero Instancia e Instrucción $n^{\circ} 3$ de la Linea de la Concepción.

El expresado principio "non bis in idem", aunque no tiene una directa expresión constitucional ha sido considerado como implícito en el art. 25.1 de la Constitución por rei- 
teradas Sentencias del Tribunal Constitucional, entre las que pueden citarse la 2/1981, 77/1983, 159/1985 y 150/1991 y recogido en numerosas sentencias del Tribunal Supremo. El principio general de derecho conocido por "non bis in idem" supone, en una de sus más conocidas manifestaciones, que no recaiga duplicidad de sanciones - administrativa y penal- en los casos en que se aprecie la identidad del sujeto, hecho y fundamento. Este principio resulta vulnerado si a consecuencia de la comisión de un solo y único hecho se impone una duplicidad de sanciones por la Jurisdicción Penal y por la Administración.

En el caso de autos no se da la triple identidad. La resolución administrativa sanciona por una infracción al patrimonio por no haberse obtenido autorización para la realización de actividades arqueológicas, siendo el bien jurídico protegido la protección del patrimonio histórico; por el contrario, las diligencias penales se siguen por desobediencia, ante el reiterado incumplimiento de los requerimientos efectuados por la Guardia Civil, en el ejercicio de sus funciones. Además tampoco existe identidad de sujetos sancionados, pues mientras que la sanción administrativa se impone a una la entidad Odyssey Marine Exploration, Inc., el procedimiento penal se sigue contra una persona fisica, capitán de un buque.

La pretendida vulneración del principio non bis in idem fue una alegación reiterada por el recurrente desde la propia vía administrativa, llegando incluso, en fase procesal y tras la formulación de la demanda, contestación y prueba, a presentar un escrito intentando hacer valer la existencia de los procesos penales como una suerte de excepción procesal que obstaculizaría la prosecución del proceso contencioso-administrativo.

Tal pretensión fue objeto de pronunciamiento específico por la Sala, con carácter independiente y antes del dictado de la Sentencia, rechazándola de plano por Providencia cuyo contenido reproducimos por entenderlo sumamente significativo:

"Por el presente recurso contencioso administrativo no se impone sanción alguna, sino que se revisa la conformidad con el ordenamiento jurídico, de la resolución sancionadora adoptada por la Administración, por lo que el pronunciamiento solicitado de vulneración del principio "non bis in idem" ha de efectuarse en sentencia.

La tramitación del presente recurso no afecta a la decisión que se pueda adoptar por la jurisdicción penal, no siendo necesario comunicación alguna al Fuzgado de Instrucción”".

No obstante, la recurrente impugnó dicha Providencia, pretendiendo la suspensión del procedimiento jurisdiccional contencioso administrativo, hasta la resolución del procedimiento penal, ya que a su entender, de lo contrario, se vulneraría el citado principio derivado del artículo 25. 1 de la Constitución, 
pretensión impugnatoria a la que nos opusimos entendiendo que la actora confundía el alcance y operatividad del principio non bis in ídem, que se proyectaba, en su caso, respecto de la resolución sancionadora, pero no sobre el proceso contencioso administrativo como revisor de la actuación administrativa impugnada. Por ello, de existir la pretendida vulneración, ésta se produciría por la imposición de la sanción, pero nunca por la revisión jurisdiccional del acto sancionador que implica el procedimiento contencioso administrativo. Precisamente, la existencia o no de la vulneración del invocado principio habría de ser resuelto en la propia sentencia, cerrando así la garantía constitucional derivada del artículo 25.1 CE.

Y eso es lo que hace finalmente la Sentencia en el Fundamento que estamos analizando, analizar, para rechazar la pretendida vulneración del principio non bis in ídem.

Ya la Resolución sancionadora realizaba un pormenorizado análisis de que no concurrían las identidades precisas para apreciar que se estaban sancionando los mismos hechos, las mismas personas y por la misma causa.

Efectivamente, dos eran las Diligencias que el recurrente trajo a los Autos, ambas tramitadas ante el Juzgado de Instrucción $n^{\circ} 3$ de la Línea de la Concepción (Cádiz), unas correspondientes al año 2006 y otras al año 2007.

Empezando por éstas últimas, las del 2007, ni siquiera se referían a estos mismos hechos, lo que por sí sólo era suficiente para excluir la aplicación del principio, pero son ilustrativas de lo que podemos calificar como una conducta reiterada de la actora contraria al obligado respeto del Ordenamiento Jurídico Español, cuando se trata de realizar actividades en territorio Español.

El propio CAB (Consejo Británico de Arqueología) calificaba a la actora de "cazatesoros" y resaltaba la "ILEGALIDAD" DE SU ACTUACIÓN Y EL "DAÑO IRREPARABLE" al patrimonio arqueológico que está causando con su forma de actuar.

Se trataba de Diligencias que se seguían por posible expolio, contrabando..., tipos delictivos que en nada afectaban a la actuación administrativa enjuiciada en el ámbito del recurso contencioso-administrativo, y que resultan perfectamente compatibles. De hecho, el que incluso la actora contara con la autorización que le habilitaba para realizar la actividad de prospección arqueológica, (cuya carencia era la determinante de la sanción administrativa), no 
podría impedir el que la actora cometiera: expolio, contrabando, daños al patrimonio cultural por imprudencia grave... Una cosa es contar con la autorización para realizar actividades arqueológicas y otra distinta es qué se hace después con los hallazgos, y es evidente que las Diligencias del 2007 abordan esta otra "faceta" de la actora.

En suma, lejos de permitir apreciar el invocado principio alegado por la recurrente con la finalidad de excluir la imposición de la presente sanción, toda la prueba practicada a su instancia ponía de manifiesto que su tónica habitual de actuación distaba mucho de ser respetuosa con el ordenamiento jurídico español.

Por lo que se refiere a las Diligencias abiertas en el 2006, sí se referían a los hechos del 10 de enero de 2006, pero el delito por el que se abren es DESOBEDIENCIA, sin que conste otro delito en esas Diligencias. Lo perseguido es la actitud de desobediencia ante la orden de la autoridad (la Guardia Civil), de que se abandonaran las actividades.

El autor de la conducta era distinto al sancionado por la Resolución Administrativa, ya que en ésta la sancionada era la recurrente, ODDYSSEY EXPLORER, en tanto que las Diligencias Penales se seguían contra el capitán del buque.

Es evidente que de una misma actuación se pueden derivar múltiples consecuencias jurídicas y eventualmente pueden ser calificadas jurídicamente desde perspectivas distintas, pudiendo hablar así de responsabilidades penales, civiles o administrativas. Es incuestionable que los bienes jurídicos protegidos en la persecución de un delito de desobediencia y la sanción impuesta por la Resolución administrativa impugnada por la falta de autorización administrativa, son absolutamente diferentes.

Efectivamente, de la actuación de la Guardia Civil se derivaron dos frentes diferentes de actuación: el administrativo sancionador por la falta de autorización y el penal por el delito de desobediencia. Los bienes jurídicos protegidos, en uno y otro caso, eran, asimismo, distintos.

\section{Incompetencia por ser el pecio propiedad del Reino Unido}

CUARTO.- Se alega la incompetencia de la Junta de Andalucía, al entender que el pecio Sussex pertenece al Reino Unido, y no siendo patrimonio andaluz no es aplicable la Ley 1/91 de Patrimonio Histórico de Andalucía. 
El Art. 52.1 de la Ley 1/91 dispone que "será necesaria la previa autorización de la Consejería de Cultura y Medio Ambiente para la realización de todo tipo de excavaciones y prospecciones arqueológicas, terrestres o subacuáticas".

No se ha acreditado de forma fehaciente, y sin lugar a dudas la realidad de la identificación del buque. Para llegar a la identificación del buque es necesaria la previa realización de prospecciones subacuáticas, que deben ser autorizadas por la Administración, con carácter previo, con la finalidad de asegurar la adecuada protección del patrimonio histórico, evitando la pérdida o la sustracción del mismo. Con independencia de la propiedad de los bienes arqueológicos encontrados, y del destino que una vez descubiertos deba darse a los mismos, toda prospección arqueológica requiere de la previa autorización administrativa.

Como una de las causas determinantes de vicio de nulidad del procedimiento sancionador seguido, se alegaba la falta de competencia de la Junta de Andalucía, porque "el pecio del Sussex pertenece al Reino Unido", lo que determinaría, según el recurrente, el primer parámetro de "incompetencia de la Junta de Andalucía para sancionar".

Tal planteamiento pretendía introducir confusión en el debate, ya que la sanción se imponía por haber realizado unas actividades arqueológicas subacuáticas sin someterse a los requisitos que establece la legislación aplicable en materia de protección del patrimonio histórico, con independencia de cuál pueda ser la pertenencia del barco a uno u otro Estado, cuestión que no era el objeto del expediente y que, ninguna incidencia tenía en la sanción impuesta.

Es más, ni siquiera los restos del buque estaban debidamente identificados, por lo que, insistimos, con independencia de cuáles fueran esos restos y su eventual pertenencia, la realidad fáctica que había sido objeto del procedimiento sancionador, era la realización de tales actividades sin autorización.

En todo caso, nada en la prueba practicada a instancias de la demandante demostró que las actuaciones en la zona se refirieran a ese pecio, el Sussex, lo que resulta particularmente interesante si se tiene en cuenta cómo unos meses después aparece toda la problemática relacionada con el "Black Swan" y el tesoro encontrado en España y que posteriormente daría lugar a una Sentencia del Juez Mark Pizzo, en Tampa (Florida), donde se juzgaba el expolio del tesoro de "La Mercedes", compuesto de 500.000 monedas de oro y plata, hecho notorio por su difusión en prensa y que puede consultarse fácilmente en Internet. Dicha Sentencia dio la razón a España. 


\section{Incompetencia de la Junta de Andalucía para sancionar en el mar territorial}

QUINTO.- Se mantiene igualmente la falta de competencia de la Funta de Andalucía por no tener competencia arqueológica subacuática en el mar territorial, limitándose la competencia a la zona marítimo-terrestre.

La sentencia del Tribunal Constitucional 38/02, tras reconocer que las competencias de las Comunidades se circunscriben a su ámbito territorial, y señalar que dentro de este se incluyen de forma indubitada los puertos y zona maritimo-terrestre, reconoce que distinto es el caso del mar territorial. Ahora bien, no declara la ausencia de competencia de las Comunidades Autónomas en el mar territorial, sino que por el contrario dispone que "en el mar territorial excepcionalmente pueden llegar a ejercerse competencias autonómicas, eventualidad ésta que dependerá, bien de un explícito reconocimiento estatutario (vertidos industriales o contaminantes en aguas territoriales, salvamento maritimo: art. 17.6 y $11 \mathrm{EAA}$ ) bien de la naturaleza de la competencia tal como resulta de la interpretación del bloque de la constitucionalidad (acuicultura: STC 103/1989, de 8 de junio ; ordenación del sector pesquero: STC 158/1986, de 11 de diciembre; marisqueo: STC 9/2001, de 18 de enero)".

El art. 13.27 del Estatuto de Autonomía de Andalucía otorga competencia exclusiva respecto de "Patrimonio histórico, artístico, monumental, arqueológico y científico, sin perjuicio de lo que se dispone el número 28 del apartado 1 del artículo 149 de la Constitución". El limite constitucional, reservado al Estado, se refiere a la defensa del patrimonio cultural, artístico y monumental español contra la exportación y expoliación. Por su parte el Real Decreto 864/84 traspasa a la Comunidad Autónoma de Andalucía, dentro de su ámbito territorial, todas las funciones sobre Patrimonio Histórico, artístico, monumental, arquitectónico, arqueológico, paleontológico, etnológico y sobre el tesoro bibliográfico y documental, a salvo de lo que disponen los artículos 149.1 y 149.2 de la Constitución.

A la vista de los preceptos legales citados, hemos de concluir que la Comunidad Autónoma de Andalucía, goza de competencia respecto del patrimonio arqueológico por expreso reconocimiento estatutario y en virtud de competencias traspasadas por el Estado, sin más limites que el derivado de las competencias exclusivas del Estado constitucionalmente reconocidas, por lo que ha de desestimarse este motivo de recurso.

La Sala rechaza así la alegación del recurrente negando la competencia de la Administración de la Junta de Andalucía, sobre la base de un pretendido reparto competencial que determinaría, a su juicio, que "de ser necesaria" la autorización, cuestión que también negaba, la misma no sería competencia de la Administración Autónoma sino del Estado. 
Con la cita de la Jurisprudencia Constitucional que recoge la Sentencia, viene a quedar claro que la titularidad demanial no es un criterio para el reparto competencial. Por lo tanto, si la protección del Patrimonio Cultural corresponde a las Comunidades Autónomas (artículo 13.27 EA, en nuestro caso) deben ser ellas quienes ejerzan la totalidad de las facultades inherentes al cometido, pues la distribución competencial en la materia no tiene por qué verse afectada porque su ejercicio se realice en tierra emergida, en el mar territorial o en la plataforma continental. Son pues las Comunidades Autónomas quienes deben autorizar las intervenciones arqueológicas subacuáticas, por ostentar la competencia exclusiva sobre la gestión y la protección del patrimonio arqueológico.

En definitiva, la calificación de dominio público estatal contenida en el artículo 132.2 de la Constitución y la delimitación del ámbito territorial de la Comunidad Autónoma no representan ningún obstáculo para el legítimo ejercicio de las competencias sobre patrimonio arqueológico subacuático con la extensión prevista en la legislación aplicable. ${ }^{3}$

\section{Incompetencia de la Junta de Andalucía y competencia del Estado en virtud del Real Decreto 799/81}

SEXTO.- Se manifiesta por último, la posible incompetencia de la funta de Andalucía al corresponder las competencias al Estado, en virtud del Real Decreto 799/81.

El Real Decreto 799/1981, de 27 de febrero regula la Investigación cientiffica-marina en zonas sometidas a la jurisdicción española, no siendo el mismo aplicable al caso de autos, por cuento la actividad pretendida no es de carácter científico-marina sino que se trata de prospección arqueológica subacuática, correspondiendo, como se indicaba en el fundamento jurídico anterior la competencia la Comunidad Autónoma.

Habiéndose reconocido la competencia de la Junta de Andalucía, hemos de concluir reconociendo la competencia sancionadora de la misma, cuando se producen vulneracio-

\footnotetext{
${ }^{3}$ La postura sostenida por la Sentencia ha sido también defendida por el Consejo Consultivo de Andalucía en el Dictamen 630/2009 sobre Conflicto de competencia acordado por el Consejo de Gobierno de la Junta de Andalucía, el 15 de septiembre de 2009, frente al Acuerdo Interdepartamental entre los Ministerios de Defensa y Cultura, sobre colaboración y coordinación en el ámbito de protección del Patrimonio Arqueológico Subacuático, de 9 de julio de 2009. Se trata de un Dictamen de gran interés por la amplitud con la que aborda la cuestión que se le plantea.
} 
nes tipificadas en relación al patrimonio arqueológico, o incumplimiento por inobservancia de la Ley 1/91 en cuanto a la obtención de las autorizaciones requeridas.

También rechaza la Sala este pretendido vicio de incompetencia sobre la base de la vulneración de una norma que, simplemente, resultaba inaplicable a los hechos objeto del procedimiento sancionador.

En efecto, los hechos sancionados, a riesgo de ser reiterativos, consistían en haber realizado unas actividades arqueológicas subacuáticas sin someterse a los requisitos que establece la legislación aplicable en materia de protección del patrimonio histórico.

Sin embargo, el RD 799/81 regula la realización de actividades de investigación científico marinas, que nada tenía que ver con la actividad del Odyssey Explorer, una prospección arqueológica subacuática, cuya regulación se contiene en la Ley 16/1985, de 6 de junio, del Patrimonio Histórico Español, Ley 1/1991, de 3 de julio, de Patrimonio Histórico de Andalucía, y el Decreto $168 / 2003$, de 17 de Junio, por el que se aprueba el Reglamento de Actividades Arqueológicas.

\section{No son aguas españolas}

SÉPTIMO.- Mantiene la parte, que no se acredita que se trate de aguas españolas al no haberse definido las líneas de base en la zona en que se realizan la excavación, condición indispensable para el reconocimiento internacional.

Ley 10/1977 del Mar Territorial en su art. 3 dispone que "el límite exterior del mar territorial estará determinado por una línea trazada de modo que los puntos que la constituyen se encuentren a una distancia de doce millas náuticas de los puntos mas próximos de las líneas de base a que se refiere el artículo anterior"; el art. 2 señala que "el límite interior del mar territorial viene determinado por la línea de la bajamar escorada y, en su caso, por las lineas de base rectas que sean establecidas por el gobierno ".

Como se reconoce en el documento del Ministerio de Asuntos Exteriores, aportado como $n^{\circ} 15$ en el escrito de conclusiones, el Real Decreto 2510/77 que define las líneas de base recta, no se han definido las mismas en la zona de la Bahía de Gibraltar, siendo la línea de base en dicha zona de bajamar escorada. Por aplicación de los arts. 2 y 3 citados de la Ley 10/77, el mar territorial alcanza hasta las doce millas náuticas desde la línea de bajamar escorada.

Como se hace constar en la resolución recurrida, la denuncia de la Guardia Civil 
mantiene que su actuación se llevó a acabo cuando se encontraban a 9 millas náuticas al sur-este de la Playa Atunara, por tanto dentro de las aguas territoriales. Dicha denuncia goza de presunción de veracidad, invirtiendo la carga de la prueba. La parte actora, no ha efectuado prueba alguna de que se encontrara fuera de las doce millas náuticas, por lo que debe presumirse que el buque se encontraba dentro del mar territorial.

La actora, discutía el lugar dónde ocurrieron los hechos, al objeto de poner en discusión que los mismos tuvieran lugar en aguas españolas. Sin embargo, se limita a negar un hecho que se fundamenta en el claro tenor del Acta de denuncia levantada por la Guardia Civil, acta en la que los agentes señalaban que los hechos se produjeron "siempre dentro de las aguas españolas...".

Se produce con ello, ante la presunción de veracidad, un desplazamiento de la carga de la prueba hacia la recurrente, prueba que no sólo no verifica sino que de la practicada a su instancia, singularmente la documental traída a los Autos desde las Diligencias Penales, viene a acreditar que el Acta de denuncia de la Guardia Civil sitúa los hechos en aguas españolas.

Los hechos ocurrieron en aguas Españolas y la cuestión que pretendía la actora introducir sobre el carácter "discutido" de la titularidad de dichas aguas, ya ha sido abordada incluso en alguna ocasión, por los Tribunales, como es el caso del Auto de 5 de junio de 2001, de la Audiencia Provincial de Cádiz, Sección de Algeciras, resolutorio de la apelación interpuesta por ésta Administración en el asunto relativo al submarino TIRELESS, Auto en el que con referencia al Tratado de Utrech de 13 de julio de 1913, se deja claro que según el mismo, el Reino Unido carece de aguas territoriales en el mar que rodea a dicho Peñón de Gibraltar.

Ninguna duda existía respecto al carácter territorial de las aguas en cuestión, sin que incluso desde la perspectiva histórica, exista reconocimiento alguno de ningún tipo de soberanía distinta de la Española.

\section{COMENTARIO}

Siendo lo suficientemente ilustrativo el análisis que se realiza de los hechos que dieron lugar a este procedimiento así como de los fundamentos de la sentencia cabe finalmente resaltar como conclusiones básicas de esta litis que se reconoce la importancia de las competencias de las Comunidades Autónomas en el patrimonio arqueológico subacuático, que se diferencia entre la titularidad del dominio público y el ejercicio de competencias en el mismo 
y que se reitera la progresiva importancia que va adquiriendo el patrimonio arqueológico subacuático tanto a nivel nacional como internacional lo que conlleva el planteamiento de cuestiones legales de diversa índole en relación al mismo. 